\title{
Os afazeres domésticos contam ${ }^{1}$
}

\author{
Hildete Pereira de Melo ${ }^{2}$ \\ Claudio Monteiro Considera ${ }^{3}$ \\ Alberto Di Sabbato ${ }^{4}$
}

\section{Resumo}

Este artigo tem como objetivo propor uma mensuração para as atividades realizadas pelas pessoas no interior dos lares, as quais têm enorme importância na reprodução da vida e no bem-estar da sociedade. Esses serviços gerados na execução dos afazeres domésticos, por não estarem associados a uma geração equivalente de renda, são ignorados pela teoria econômica que não os valora e não contabiliza no Produto Interno Bruto (PIB) dos países. Uma provável interpretação para esse nãoreconhecimento origina-se na histórica discriminação sofrida pelas mulheres nas diversas sociedades, a quem foi delegada a execução dos afazeres domésticos. Desconhecê-los reforça o conceito de invisibilidade, que caracteriza o trabalho doméstico e a inferioridade do papel da mulher na sociedade. Tendo por base os procedimentos usuais de estimativas de bens ou serviços não mensurados por estatísticas econômicas, estatísticas demográficas e sociais originárias da Pesquisa Nacional por Amostra de Domicílios (PNAD) que, desde 2001 investiga o tempo gasto na execução de tarefas domésticas, chega-se à conclusão de que, no Brasil, esses afazeres corresponderam, em média, a 11,2\% dos PIBs brasileiros do período 2001-2005.

Palavras-chave: Mulheres - Trabalho; Trabalho feminino - Brasil; Contas nacionais - Brasil;

\section{Abstract}

\section{Accounting for housekeeping activities}

This paper proposes a measurement for housekeeping activities, which play an enormous role in the reproduction of life and in the well-being of society. These housekeeping activities are ignored in economic theory, which neither values them nor accounts for them in the Gross Domestic Product measures, as far as they are not associated with an equivalent flow of monetary revenue. A plausible interpretation for this non-consideration derives from the historical discrimination, in most societies against women, to whom the carrying out of housekeeping activities has been delegated. Ignoring housekeeping activities reinforces the concept of invisibility, which characterizes domestic labor and

(1) Trabalho recebido em janeiro de 2006 e aprovado em maio de 2007. Uma versão preliminar deste artigo, submetida à apreciação desta revista, foi publicada como Texto para Discussão, n. 171 da Faculdade de Economia da Universidade Federal Fluminense (UFF). Com a divulgação de novas informações (PNADs e Novas Contas Nacionais) do IBGE, o artigo foi atualizado até 2005. Os autores agradecem os comentários e as sugestões de dois pareceristas anônimos desta revista e a de participantes em seminários em que o artigo foi apresentado.

(2) Professora Associada da Faculdade de Economia da UFF, doutora em Economia. Editora da revista Gênero/UFF, Niterói, RJ, Brasil. E-mail: <hildete@economia.uff.br>.

(3) Professor Adjunto da Faculdade de Economia da UFF, Niterói, RJ, Brasil. Ex-diretor de pesquisa do Ipea (1993-1998), ex-Secretário da SEAE do Ministério da Fazenda (1999-2002) e ex-chefe das Contas Nacionais do IBGE (1986-1992). E-mail: <cmconsidera@economia.uff.br>.

(4) Professor Adjunto e Diretor da Faculdade de Economia da UFF, Niterói, RJ, Brasil. E-mail: <alberto@economia.uff.br>.

Economia e Sociedade, Campinas, v. 16, n. 3 (31), p. 435-454, dez. 2007. 
Hildete Pereira de Melo / Claudio Monteiro Considera / Alberto Di Sabbato

the inferior role of women in society. With basis on usual procedures to estimate goods or services not measured by economic statistics, and using demographic and social statistics from the National Survey through Household Samples (PNAD), which since 2001 inquires about the time spent in doing domestic activities, we find that housekeeping activity corresponds on average to $11,2 \%$ of Brazilian GDP of 2001-2005 period.

Key words: Housekeeping activity; National accounts; Invisibility of female work. JEL B54.

\section{Introdução}

Desde 1975, que a Organização das Nações Unidas (ONU) instituiu como o Ano Internacional da Mulher, a condição feminina passou por profundas transformações. Da leitura biologizante de Freud, onde "anatomia é destino", para a idéia de que "não se nasce mulher, torna-se mulher", como afirmou Simone de Beauvoir (1949), muitas lutas foram travadas pelo movimento de mulheres, internacional e nacional, para mudar sua milenar situação de subordinação.

O papel feminino assentado na reprodução biológica, com ênfase na maternidade e na realização de afazeres domésticos, definiu o lugar da mulher na esfera privada e, seu contraponto, o papel masculino no exercício do poder econômico na esfera pública. Essa dicotomia entre os papéis masculino e feminino, embora esteja traçada ao longo dos séculos nos seus aspectos fundamentais, e consagrada numa relativa divisão sexual do trabalho, tem variado bastante ao longo da história da humanidade.

$\mathrm{O}$ ascenso do movimento de mulheres, nas últimas décadas, questionando os velhos estereótipos sobre o papel feminino, abriu novas possibilidades e oportunidades na sociedade para o surgimento de atividades fora do lar realizadas pelas mulheres. Isso foi favorecido pelo acesso à educação, que tanto provocou a incorporação de um maior contingente de mulheres no mercado de trabalho ${ }^{5}$ como aumentou sua participação política na sociedade. Embora essa trajetória do "progresso feminino" seja mensurada pelas Ciências Sociais através de indicadores econômicos e sociais relacionados à esfera pública e aponte para as transformações em curso, estas nada dizem a respeito das funções tradicionais que as mulheres exercem secularmente e que permanecem como encargo específico feminino. Embora se tenha tido acesso à educação, trabalho assalariado, participação social e política, como Janus, as mulheres têm uma face voltada para o lar e a outra para a rua, num grande esforço de sobrevivência, num tempo de ruptura de um código milenar.

(5) As mulheres pobres, com baixos níveis de renda, sempre trabalharam nas esferas privada e pública. Sejam como escravas no eito ou na cidade como vendedoras ambulantes, amas-de-leite, escravas de ganho, isto no século XIX, seja como as atuais domésticas/diaristas. As mulheres pobres foram e são presenças marcantes no mundo do trabalho ao longo de nossa história. 
Mas essa mudança no papel feminino ao longo destas últimas décadas não teve como contrapartida uma transformação no papel masculino. Porque, na verdade, os papéis de cada ator social são desempenhados em interação com o outro, relação de troca e reciprocidade: se um muda o outro tem que mudar. $\mathrm{O}$ papel feminino mudou sem que o papel masculino fosse fundamentalmente tocado. No caso brasileiro, isso é agravado pelas enormes desigualdades existentes entre as classes sociais, que permitiram que essa incorporação maciça de mulheres no mercado de trabalho tenha sido efetuada sem maiores mudanças nas relações de gênero. As empregadas domésticas são um exército de mulheres pobres, com baixa qualificação, custos baixíssimos e representam o maior contingente de trabalhadoras do país. A existência dessas trabalhadoras possibilita que a prestação, pelas mulheres, dos serviços domésticos não seja interrompida e continue sobre os ombros femininos, mesmo na ausência da mãe/esposa no lar. Muitas propostas políticas foram feitas no âmbito internacional para assegurar igualdade entre mulheres e homens no acesso aos benefícios sociais e equipamentos públicos que possibilitassem a retirada de certos serviços do interior dos domicílios e para aliviar a vida das mulheres desses encargos. Mas isso tem permanecido como uma lista de boas intenções.

As questões acima mencionadas levaram os autores a escrever este trabalho, juntando militância feminista com a experiência de coordenação das Contas Nacionais brasileiras e do tratamento dos dados econômicos, para propor uma metodologia para incluir na contabilidade do Produto Interno Bruto (PIB) uma forma que possibilite a mensuração dos afazeres domésticos. Claro que este exercício metodológico foi possível devido à implementação de levantamentos estatísticos que mensuram o uso do tempo pelas populações e isso permite analisar a reprodução econômica e social - do trabalho remunerado até os afazeres domésticos. Esses levantamentos foram feitos em alguns países da União Européia, Estados Unidos, Canadá e Brasil (Dedecca, 2004).

Este estudo está organizado da seguinte forma: primeiro faz uma breve discussão sobre o significado da invisibilidade do trabalho feminino na realização das atividades organizadas no âmbito da família, em seguida discorre sobre a metodologia da medição das contas nacionais e em terceiro apresenta a proposta de inclusão dessas atividades na contabilidade do PIB.

\section{A invisibilidade do trabalho da mulher}

Desde os anos 1970 que o movimento feminista vem questionando os paradigmas científicos do mito da neutralidade da ciência e as teorias deterministas biológicas que fazem uma leitura biológica e naturalizante da condição feminina (Aguiar, 1997). As ciências biológicas são herdeiras da antiga tradição filosófica grega que considerava que nascer mulher era uma punição dos 
deuses e que o único destino dos seres femininos era procriar. Essa percepção levou a que as ciências se desenvolvessem baseadas no princípio da inferioridade feminina, escamoteando que durante séculos as mulheres acumularam experiências e aprendizado na arte de curar e na obstetrícia.

As Ciências Humanas tampouco fugiram à regra e tratavam as mulheres no âmbito da estratificação social limitada aos estudos sobre a família, nos quais as mulheres reinavam. O casamento aparecia como uma das carreiras mais honrosas, o que dispensava de qualquer participação social, tornando o sexo feminino ignorado enquanto ator social. A família era considerada uma estrutura que atravessava a história, linear na sua evolução e perene quanto à composição de seus membros.

A ideologia da natureza feminina criou uma cortina de fumaça que obscureceu as formas de viver das mulheres; a rigor, na produção acadêmica, as mulheres apareciam e aparecem como uma categoria estatística. Recebem salários mais baixos que os homens, apresentam taxas de rotatividade mais altas no seu trabalho, atuam preferencialmente no setor serviços e, na indústria, estão concentradas em alguns ramos manufatureiros. Mas a ciência necessita ir além disso. ${ }^{6}$

A produção atual sobre a condição feminina nas Ciências Humanas é, de certa maneira, caudatária do movimento de mulheres que, ao longo dos últimos trinta anos, institucionalizou-se nesse formato e desenvolveu debates de forma autônoma em relação ao próprio movimento. Influenciadas tanto por um quadro teórico marxista como neoclássico, a história, a sociologia, a antropologia, a política e a economia tiveram seus paradigmas numa e noutra vertente invadidos pelo olhar de gênero e muitos estudos e pesquisas foram produzidos, tentando dar conta dessa realidade.

A maioria dos temas arrolados na academia refere-se à problemática do trabalho feminino, da saúde reprodutiva, participação política e família. Uma das temáticas mais recorrentes é a da invisibilidade do trabalho da mulher, numa discussão, sobretudo com a economia, sobre a desqualificação do trabalho doméstico. Esse é um dos temas mais antigos trazidos pelo feminismo para as ciências sociais e está referenciado a uma tentativa de reinterpretar os conceitos de trabalho doméstico e trabalho produtivo/improdutivo e funciona como um iceberg para a questão da inferioridade feminina. A respeito da importante questão sobre por que o trabalho doméstico é executado predominantemente por mulheres, as diversas ciências sociais, sobretudo a teoria econômica per se, têm pouco ou nada

(6) Sobre as ligações entre ciência e gênero, ver Keller (1985); Harding (1986); Sayers (1989); Nelson (1992); Scavone (1996); Aguiar (1997). 
a dizer e as análises econômicas tampouco avançaram além de idéias e preconceitos de seus autores.

Essa questão permanece obscura porque, tanto na visão liberal como na marxista, a subordinação feminina é explicada pela sua exclusão do mundo mercantil e essa exclusão devia-se a razões culturais. A visão da vida humana e da organização social de Marx é o seu conceito de produção: "A produção da vida, tanto da própria, no trabalho, como de vida nova na procriação, surge agora como um duplo relacionamento: por um lado, como relacionamento natural, por outro, como relacionamento social" (Ideologia Alemã). Com tanta ambigüidade, Marx, na sua principal obra - $O$ capital -, não faz referência à questão da família e a reprodução dos seres humanos permanece nebulosa.

Marxistas-feministas argumentam que as mulheres na esfera doméstica são exploradas por seus companheiros, sejam eles trabalhadores ou capitalistas, pois os afazeres domésticos são o tipo mais comum de trabalho não pago. Essas análises partem da idéia de Marx de que a força de trabalho é uma mercadoria especial cujo valor de uso é produzir valor (de troca). No processo de (re)produção dessa mercadoria especial ocorre um segundo tipo de exploração, pois o trabalho doméstico para uso da própria família, invariavelmente feito por mulheres, não é pago nem socialmente reconhecido. Pode-se concluir que a "troca" entre capital e trabalho não é uma relação mercantil e não é possível explicar o surgimento do lucro e a reprodução da relação salarial exclusivamente no âmbito da produção e circulação de mercadorias. Não há equivalência na "troca" entre capital e trabalho, mas apenas uma igualdade de estatuto jurídico em sua relação contratual. Não é uma relação de troca entre portadores de mercadorias, e sim uma relação desigual de poder garantida e regulada pelo Estado. ${ }^{7}$

Dessa forma, o exame dessa questão implica uma análise não economicista do capitalismo. Nesse nível de abstração, o trabalho é cego ao sexo; como a sociedade mercantil se baseia na concorrência intra e intercapitalistas e trabalhadores, o sexo, juntamente com a raça e a educação, consistiria um dos fatores de clivagem dessa concorrência, funcionando como álibi para a discriminação. Na realidade, o capital em geral tenta reproduzir as condições de estabilidade do organismo social. Mas o movimento é contraditório e, como disse Kalecki (1979), "os capitalistas não agem como classe"; quando a dinâmica da acumulação se choca com a ordem social preexistente, o capitalismo a destrói. A acelerada incorporação das mulheres no mercado de trabalho nas últimas décadas ilustra essa problemática.

(7) Ver as citações sobre Marx nos trabalhos: Bennetti e Cartelier (1981); Cartelier (1980); De Vroey (1984); Machado e Serrano (1986); Lopes e Serrano (1987). 
Como a produção doméstica é de valores de uso, não há em "O capital" referência à questão da família; a reprodução dos seres humanos permanece nebulosa. Pensar essa questão envolve incorporar a produção doméstica não mercantil aos postulados da teoria econômica. Esta permite a reprodução dos seres humanos, portanto dos trabalhadores para o capital. O ocultamento das tarefas domésticas, como algo que foge ao escopo da teoria, porque não é objeto de troca na sociedade, foi tratado pelas feministas marxistas como a construção da imagem partida da mulher, de cidadã de segunda categoria. Para elas a diferença entre valor de uso e valor de troca ou trabalho concreto e trabalho assalariado não é pequena e é fundamental tratá-los separadamente. Isso é agravado pelo fato de não haver nenhum estudo bem-feito tratando a questão da reprodução, trabalho doméstico, socialização das crianças e cuidado com os idosos e doentes (tarefas típicas femininas). Essas tarefas, que antes eram organizadas por meio de relações de parentesco e inseparáveis em relação a sexo e classe são, no capitalismo, tratadas separadamente e mantêm uma íntima relação com a situação de inferioridade da mulher no mundo atual.

É preciso ressaltar que as teses de Marx, diante de outras correntes econômicas, tiveram grande impacto na divulgação de textos sobre a subordinação feminina e inspiraram inúmeros trabalhos na interface da economia com a sociologia e a antropologia. Essas pesquisas partiam da idéia de que a subordinação das mulheres é explicada pela exclusão do mundo mercantil, analisavam os impactos da industrialização sobre a vida das mulheres focalizando a ótica da produção, mas seguindo a tradição, deixavam de lado o seu papel reprodutivo. ${ }^{8}$

Assim, as correntes econômicas, tanto clássica, como marxista, obscurecem as relações de gênero nas interpretações dos conceitos de produção e reprodução no capitalismo (Mill, 1985 e Melo; Pena, 1985). No Brasil, os trabalhos pioneiros sobre esse tema foram de Saffioti (1976) e Blay (1978); a primeira autora incorporou à sua análise a noção da mística feminina em paralelo com a de exército industrial de reserva. Combina a idéia da ternura feminina com reserva de mão-de-obra usada pelo sistema capitalista para rebaixar o preço da força de trabalho, padecendo da problemática tratada acima. Blay, preocupada com a redução do emprego feminino manufatureiro, decorrente do advento da industrialização nos países periféricos, apresenta também conclusão similar à de Saffioti.

A visão neoclássica do trabalho doméstico foi revisitada nas últimas décadas principalmente pelo economista norte-americano Gary Becker (prêmio

(8) Ver sobre o assunto, ainda, Michel (1978); Meillassoux (1979); Nicholson (1987); Tahahite (1984). 
Nobel de Economia de 1992). ${ }^{9}$ Para este, a mãe enquanto agente "econômico" tem seu comportamento analisado a partir da idéia de otimização, isto é, a idéia do agente econômico otimizador baseia-se no pressuposto da concorrência intercapitalista como um processo de seleção que impele os agentes (empresas) a tentarem maximizar o lucro. Tratando-se de consumidores, estes são individualistas e utilitaristas e as mulheres no exercício da maternidade comportam-se como tal.

Entretanto, as pessoas não se comportam como empresas capitalistas nem se pode classificar o ato de ter filhos como uma relação utilitarista. Não que as mães sejam benevolentes e altruístas, mas o comportamento materno egoísta provavelmente colocaria a sobrevivência infantil em risco. Portanto, fica difícil justificar a análise dos afazeres domésticos a partir da hipótese de otimização.

Há problemas também com a noção de equilíbrio utilizada por Becker. $\mathrm{Na}$ teoria neoclássica, a justificativa para o estudo de posições de equilíbrio do mercado está baseada na idéia de que, em condições competitivas, desequilíbrios entre oferta e demanda fatalmente geram reações das empresas que buscam o lucro. Essas reações tendem a eliminar rapidamente tais discrepâncias. Logo, embora a economia na realidade jamais esteja em equilíbrio, estará sempre tendendo ao equilíbrio entre oferta e demanda.

Becker faz suas análises usando a hipótese de que o "mercado" virtual de trabalho doméstico está sempre em equilíbrio, ou seja, que qualquer transação necessariamente é uma transação de equilíbrio entre dois agentes que estão otimizando. Isso aproxima sua análise de uma tautologia. Se algo ocorre (por exemplo, uma mulher tem um filho) necessariamente isso foi resultado de uma ação racional dela (e também do pai da criança), na qual a utilidade de ter mais um filho se iguala ao custo marginal de criá-lo. Além disso, como o trabalho (afazer) doméstico não é feito sob condições de concorrência, estão ausentes as principais forças que justificam a idéia de que a economia ao menos tende ao equilíbrio.

Assim, a Teoria Econômica tal como foi formulada por economistas clássicos, marxistas e neoclássicos, aplicando seus pressupostos, tais como concorrência, oferta, demanda, luta de classes, etc., conceitos usados para estudar o mercado capitalista, é inadequada para explicar a condição feminina na nossa sociedade. É necessário outro tipo de instrumental que privilegie instituições, padrões culturais, estratégias de discriminação, questões psicossociais para desvendar o real sentido do feminino em nossa sociedade.

(9) Ver bibliografia sobre Becker, nas referências. Os próximos itens estão baseados num texto escrito pela autora em parceria com Serrano (1997). 
A repercussão do movimento feminista levou à formulação do conceito de gênero, e os vários campos do saber o têm incorporado como uma teia de relações de poder que se estabelecem entre as mulheres e os homens (Scott, 1994). Na realidade, deve-se repensar a família, não mais como um conjunto homogêneo, mas uma situação de convivência entre indivíduos de sexos diferentes que realizam atividades produtivas e reprodutivas, compartilhando um projeto de sobrevivência. O problema é que o desconhecimento da especificidade da contribuição das mulheres leva a aumentar a subestimação das práticas por elas exercidas no espaço familiar e no produtivo, acentuando a idéia do subemprego feminino. A invisibilidade que cerca o estudo das diferenças de gênero fortalece a reprodução das desigualdades junto às possibilidades e às oportunidades de emprego que podem ser oferecidas às mulheres pelo desenvolvimento.

Ester Boserup (1970), no seu trabalho pioneiro, definiu a divisão sexual do trabalho como um elemento de base na divisão do trabalho. A autora apontou como, no cálculo do produto nacional, na produção e nos serviços de subsistência, as atividades realizadas pelas mulheres e suas contribuições ao bem-estar socioeconômico são subestimadas ou a elas não se dá a devida importância. As críticas realizadas pelas feministas no final dos anos 1970 ajudaram a ampliar a discussão sobre as formas de valorizar o papel das mulheres nas duas instâncias sociais: a reprodução e a produção.

Esse enfoque mais amplo evidencia que a plena participação das mulheres pode ser visualizada através da eliminação das limitações que as marginalizam ou as tornam invisíveis, seja nas atividades domésticas, seja nas atividades públicas e produtivas. O trabalho de Ann Oakley (1974) ao explicitar a relação do homem ao trabalho produtor de mercadorias, e da mulher à casa, conclui que o termo donade-casa não pode ser sinônimo de esposa e mãe, mas de trabalho doméstico não remunerado. Isso colocou mais lenha no fogo da rebelião feminina ao não aceitar mais os velhos estereótipos do papel feminino e desmascarar o trabalho não pago.

Desde os anos 1980, o feminismo acadêmico formulou a categoria gênero para analisar o trabalho feminino, através do estudo da divisão sexual do trabalho e da injustiça social. A utilização do conceito de gênero embute a idéia de que as relações sociais constituem-se em relações antagônicas e conflitivas. A utilização desse conceito também embute o estudo das implicações das diferenças entre os papéis econômico e social das mulheres e dos homens facilitando a superação da desvalorização atribuída aos trabalhos realizados pelas mulheres. Esta nova perspectiva de gênero está voltada a reconhecer que tipo de especificidade e de colaboração existe entre os papéis desempenhados pelos homens e mulheres. Nesse sentido, o interesse é resgatar o conjunto diversificado dos papéis desempenhados pelas mulheres, considerando-as como agentes/atores e não exclusivamente como indivíduos beneficiados no interior homogêneo dos núcleos familiares ou invisíveis no interior da população. 
Pensamos, assim, que a perspectiva de gênero possibilita uma avaliação mais rica sobre a quantidade e a qualidade das mudanças que as mulheres vivenciaram nas últimas décadas, devido às transformações acontecidas em todas as atividades econômicas. Esse reconhecimento implica reavaliar a metodologia de cálculo da contabilidade nacional que vela o trabalho doméstico e dessa forma não reconhece sua enorme importância para o bem-estar da sociedade.

\section{$2 \mathrm{O}$ que medem as contas nacionais}

O Sistema de Contas Nacionais segue basicamente as recomendações das Nações Unidas (ONU), do Fundo Monetário Internacional, da Comissão das Comunidades Européias, da Organização para a Cooperação e Desenvolvimento Econômico e do Banco Mundial explicitadas no manual das Contas Nacionais System of National Accounts, 1993 [(SNA), IBGE. 1997; 2007]. Essas recomendações são no sentido de que se adote um conceito amplo de produção. Assim sendo, considera-se como produtiva toda operação socialmente organizada para a obtenção de bens e serviços, sejam eles transacionados ou não no mercado, a partir de fatores de produção transacionados no mercado. Ela é realizada por residentes no território econômico nacional, refere-se a um dado período de tempo e é valorada, nas estatísticas brasileiras, a preços básicos, ou seja, inclui os custos de produção e os impostos líquidos de subsídios às atividades.

A produção de bens e serviços é considerada mercantil sempre que ela puder ser comercializada a um determinado preço estabelecido em mercado. Toda a produção de bens ${ }^{10}$ é considerada, por convenção, mercantil, isto é, existe um mercado para aquele bem, de forma a se poder inferir um preço e, portanto, um valor da produção. Isso inclui toda a produção para autoconsumo da agricultura e a produção por conta própria de bens de capital fixo imobilizados pelo próprio produtor.

Já os serviços ${ }^{11}$ são divididos em mercantis e não mercantis. São considerados mercantis aqueles cujo objetivo de produção é a venda no mercado por um preço que remunera os serviços dos fatores usados na sua obtenção. Inclui, ainda, um serviço cujo valor é obtido por convenção, como se verá adiante no tratamento das Instituições Financeiras: a produção imputada de serviços de intermediação financeira.

Os serviços não mercantis são aqueles fornecidos à coletividade (todo o país, grupos específicos de pessoas ou famílias, etc.) gratuitamente ou por um

(10) Os bens são associados a alguma coisa tangível, sendo muitas vezes chamados de bens transportáveis.

(11) A literatura econômica não conta ainda com uma definição comum de ampla aceitação do que sejam serviços. De uma maneira geral, "serviços" designam atividades diferentes das atividades produtoras de bens agropecuários e industriais. Simplificando, é tudo o que não pode ser estocado pelo produtor (ver Melo et al., 1998).

Economia e Sociedade, Campinas, v. 16, n. 3 (31), p. 435-454, dez. 2007. 
preço simbólico. Esses serviços coletivos são fornecidos pelas administrações públicas ou por instituições privadas sem fins lucrativos. Estas são definidas como unidades institucionais cujo principal objetivo é atender as famílias e cuja principal fonte de financiamento é a transferência compulsória ou voluntária de recursos através de impostos, doações, etc.

Uma parcela desses serviços coletivos fornecidos pelas administrações públicas não possui nenhum tipo de mercado (defesa nacional, o poder judiciário, etc.), não se podendo, assim, definir seu preço sob nenhuma hipótese e, portanto, seu valor da produção. Entretanto, outra parcela dos mesmos (saúde, educação públicas, etc.), e parte dos serviços privados não mercantis poderiam ser valoradas por preços de mercado dos seus congêneres mercantis. Entretanto, esses serviços, quando mercantis, têm uma parcela considerável de excedente operacional bruto no seu valor adicionado que inclui diversas outras remunerações que não o trabalho. Como a administração pública não gera excedente (a menos de eventuais valores de depreciação do capital fixo), buscando-se garantir a homogeneidade dos conceitos, considera-se como valor da produção dos serviços não mercantis, sejam públicos ou privados, o seu custo de produção. Ou seja, a soma do valor dos bens destinados ao consumo intermediário dos produtores dos serviços não mercantis, com valor das remunerações (salários brutos mais encargos sociais) e da depreciação (consumo de capital fixo).

Como serviços não mercantis incluem-se, ainda, os serviços domésticos remunerados, prestados por trabalhadores autônomos. Seu valor da produção é medido pelo valor das remunerações dos trabalhadores autônomos ocupados nessa atividade. Portanto, exclui o serviço doméstico executado por conta própria e sem remuneração.

Fica claro, portanto, que as contas nacionais medem todos os bens e serviços que envolvam a remuneração dos fatores de produção, fazendo com que prevaleça a identidade na qual o produto é igual à renda. Vale dizer, a utilização de fatores de produção no processo de produção gera o equivalente em remunerações ao que o fator de produção contribuiu para o produto em adição de valor.

É necessário citar aqui duas situações interessantes, o que implica considerar situações fictícias de maneira a se proceder com a maior acuidade possível à mensuração da produção pelo agente responsável por ela. Uma delas refere-se a se considerar como produção das instituições financeiras a diferença dos juros recebidos e dos juros pagos, valor que de fato foi gerado em outro momento da produção. De fato, essa diferença de juros não é produzida pelas instituições, mas sim por elas apropriada. ${ }^{12}$

(12) Esse valor será posteriormente retirado do valor adicionado para evitar sua dupla contagem. 
Outra situação refere-se ao valor imputado de aluguéis aos imóveis de uso próprio. Ou seja, os imóveis geram um serviço de ocupação (moradias, instalações agrícolas, industriais, ou de serviços) que, quando se refere aos imóveis alugados, é medido pelo valor do aluguel; quando os imóveis são usados pelo proprietário, esse mesmo serviço gerado é medido pelo valor de aluguéis de imóveis alugados de características semelhantes. Vale dizer, o bem de capital imóvel de uso próprio gera um valor de serviço equivalente ao valor do seu aluguel ou, se de uso próprio, imputa-se um valor fictício equivalente ao valor que teria seu aluguel.

No caso do trabalho doméstico observa-se que, quando exercido por terceiros, seu valor equivale ao valor de sua remuneração. Entretanto, quando exercido por alguém da própria família ele não é computado nas contas nacionais. Por que razão, como se viu no parágrafo anterior, ao fator de produção trabalho não se dá o mesmo tratamento que ao fator capital? Adicionalmente, do ponto de vista do mercado de trabalho, as pessoas que exercem apenas afazeres domésticos - as donas-de-casa, sequer são consideradas como força de trabalho (PEA) - são classificadas como população inativa. Curiosamente, se estiverem exercendo, mesmo que sem remuneração, atividades em um empreendimento familiar, são tratadas como população ocupada.

É útil notar que o SNA, no seu capítulo VI (a conta de produção), discute essas questões e justifica por que os afazeres domésticos devem ser excluídos do cálculo do PIB. ${ }^{13}$ Argumenta, exemplificando com a produção de bens agrícolas ou industriais para uso próprio, que estes podem se destinar alternativamente ao mercado, enquanto os serviços de uso próprio (afazeres domésticos) não têm essa qualidade, pois não exprimem a realidade do mercado capitalista. Além disso, justifica a imputação dos aluguéis devido a uma pretensa grande diferença, entre países, na proporção de imóveis alugados e imóveis próprios.

Se essa é uma justificativa razoável, pode-se argumentar que há também uma grande diferença na disponibilidade de bens e serviços auxiliares mercantis existentes entre os diversos países que reduzem o tempo dos afazeres domésticos; por sua vez, esses bens e serviços mercantis criam valores que são computados no PIB, reduzindo o PIB dos países em que os afazeres domésticos são mais freqüentes e realizados pelas próprias famílias.

Portanto, caso os afazeres domésticos viessem a serem considerados nas contas nacionais deveriam ser tratados como produção de serviços não mercantis, produzidos pelas famílias e por elas integralmente consumidos. Isso implicaria a

(13) O capítulo VI no item 6.17 afirma: "A fronteira de produção no Sistema é mais restrita que a fronteira de produção geral. ....as contas de produção não são elaboradas para as atividades das famílias, que produzem serviços domésticos ou pessoais para consumo final próprio, excepto os serviços produzidos pelo emprego de pessoal de serviço doméstico remunerado".

Economia e Sociedade, Campinas, v. 16, n. 3 (31), p. 435-454, dez. 2007. 
criação de uma atividade produtiva "família" análoga à atividade "administração pública" cujo valor da produção seria medido de forma idêntica à dos serviços domésticos remunerados.

\section{A importância dos afazeres domésticos no Brasil}

Contabilizar o valor dos afazeres domésticos no PIB do país talvez não atraia o mesmo tipo de atenção em países mais desenvolvidos que o Brasil, bem como para países em que a discriminação da mulher seja menos perceptível que aqui. Quanto ao primeiro aspecto, no Brasil e nos países menos desenvolvidos, predominam altas taxas de desemprego associadas aos baixos salários que geram a exclusão voluntária do mercado de trabalho de um grande contingente de pessoas em idade ativa. Para essas pessoas, o custo de oportunidade entre exercer uma atividade remunerada ou se dedicar a afazeres domésticos (cozinhar, limpar, lavar, cuidar dos filhos, dos doentes e idosos) não compensa.

Nos países mais desenvolvidos, com maior oferta de empregos para pessoas qualificadas, a balança pende ao contrário. Tendo em vista o elevado custo de se contratar trabalhadores para serviços domésticos, foi desenvolvida uma série de facilidades (no tocante a creches, escolas, alimentação e limpeza) que torna possível aos casais exercerem atividades remuneradas e dar conta dos afazeres domésticos.

Por sua vez, a produção pelo mercado dessas facilidades leva ao crescimento do PIB nos países mais desenvolvidos. A despeito de não serem contabilizados (valorados e contados), os serviços produzidos pelos afazeres domésticos contribuem, de fato, para aumentar a disponibilidade de serviços da família e, portanto, para aumentar o bem-estar familiar. A diferença entre os dois, o gerado pelo serviço doméstico remunerado e o criado pelo sem remuneração é, unicamente, gerar ou não um fluxo de rendimentos.

Portanto, sua mensuração no Brasil e nos países menos desenvolvidos é particularmente relevante se as contas nacionais pretendem de fato medir a disponibilidade efetiva de bens e serviços da nação. É bem provável que o valor desses serviços seja também importante nos países mais desenvolvidos, a despeito de que o número de horas a venha a ser, provavelmente, menor. A importância do seu valor decorreria do fato de esses serviços domésticos serem consideravelmente mais bem pagos nesses países.

Quanto ao segundo aspecto, os afazeres domésticos são historicamente atribuições da mulher. Embora, atualmente, a discriminação da mulher seja menos predominante nos países mais desenvolvidos, a não-contabilização (valorização) dos afazeres domésticos como produto da nação deriva, provavelmente, do papel inferior a que foi relegada a mulher no passado. Pode-se, mesmo, radicalizar e 
dizer que parte da subsistente discriminação da mulher, mesmo nos países mais desenvolvidos, deriva da não-contabilização (valorização) desses afazeres no PIB. Mostrar o quanto eles valem e contribuem para o bem-estar familiar e do país talvez ajude a reduzir essa discriminação.

\section{Proposta metodológica para medir os afazeres domésticos no Brasil}

Desde 2001 a Pesquisa Nacional por Amostra de Domicílios (PNAD) do IBGE investiga o número de horas despendido pela população na execução de afazeres domésticos por unidade da federação, classificando-as por gênero e faixa etária. Graças à introdução dessa questão na pesquisa lé que foi possível fazer esta proposta metodológica.

Os afazeres domésticos são exercidos tanto por homens como mulheres, embora o número de horas destas seja bem superior ao daqueles. ${ }^{14} \mathrm{O}$ ideal seria procurar identificar os diferentes tipos de atividades domésticas e as remunerações específicas médias (por hora) de cada uma delas, segundo a Pesquisa Nacional por Amostra de Domicílios (PNAD/IBGE) e multiplicar pelo número de horas observado para cada tarefa doméstica, de acordo com as informações da mesma pesquisa.

Evidentemente que, como qualquer estimativa, sobreviriam diversos problemas nessa mensuração. Se, no caso dos imóveis, de alguma forma se procura medir serviços de qualidade semelhante (com escasso sucesso), isso se torna impossível no caso do trabalho doméstico. Esses serviços são prestados por pessoas de qualificações diferentes e o mercado impõe remunerações pelo resultado obtido. Em termos da produção de estatística desses serviços não remunerados, essas qualidades não são de fácil mensuração de forma a se estabelecer valores equivalentes. A imputação de remuneração média por hora de trabalho é a solução possível.

Outro problema seria associado às tarefas domésticas que usassem bens intermediários da construção (tinta ou cimento, por exemplo) que já estaria sendo contabilizado na produção da construção de autônomos, já que a construção por conta própria já é medida nas contas nacionais pelo uso dos insumos típicos da construção.

Feitas as contas, o valor da renda (ou produto) obtido seria adicionado ao valor da renda gerada no setor serviços - serviços domésticos e dessa forma adicionado ao PIB do país. Seria um procedimento semelhante ao que se usa para expandir a produção de atividades não mensuradas pelas estatísticas econômicas e que no Brasil tem correspondido a cerca de $13 \%$ do PIB brasileiro.

(14) Como se verá adiante, em quase todas as faixas etárias é duas vezes maior. 


\section{O uso da Pesquisa Nacional por Amostra de Domicílios (PNAD/IBGE)}

A Pesquisa Nacional por Amostra de Domicílios (PNAD/IBGE) investiga, desde o ano de 2001, o número de horas despendido na execução de afazeres domésticos por unidade da federação, classificando-o por sexo e faixa etária.

A mesma pesquisa (PNAD) investiga também o tipo de atividade econômica, o número de horas trabalhadas, e a respectiva remuneração das pessoas ocupadas na produção, quer elas tenham ou não carteira assinada, quer sejam empregados ou empregadores. De fato, para várias atividades econômicas, esta é a única informação a respeito da produção e, graças a ela, é possível imputar nas contas nacionais valores adicionados que não são registrados pelas estatísticas econômicas do país ou mesmo por registros administrativos.

Assim, a partir das informações da PNAD, as contas nacionais do Brasil podem medir também a produção dos trabalhadores domésticos remunerados. $\mathrm{O}$ que se propõe aqui é o seu uso para mensurar também os afazeres domésticos executados por membros das famílias não remunerados. Para isso, utilizou-se a remuneração média dos serviços domésticos remunerados, por estado, por hora e multiplicou-se pelo número de horas de afazeres domésticos, por estado, sexo e faixa etária. ${ }^{15}$ Cabe aqui uma questão que foi com relativa freqüência mencionada em diversas discussões sobre o tema. Por que atribuir o valor recebido por empregadas domésticas quando semelhante serviço é prestado por pessoas de qualificações superiores à maior parte do universo das empregadas domésticas? A resposta para isso é simples: caso um (a) engenheiro (a) ou economista com doutorado ou outra qualquer profissão oferecesse seus préstimos no mercado de serviços domésticos, ele/ela seria pago pelo valor de mercado atribuído aos prestadores desse serviço. Sua remuneração não seria aquela da sua profissão. Seria equivalente à de uma empregada doméstica.

Lembramos que, como a PNAD vai a campo em setembro de cada ano, menos naqueles em que se realizam os censos, as informações registradas nesta pesquisa referem-se ao mês de setembro do ano de referência. De acordo com a metodologia aplicada pelo IBGE para o cálculo das contas nacionais do Brasil, é mais correto utilizar para esta simulação as variações mensais do rendimento médio dos serviços domésticos, conforme registrado pela Pesquisa Mensal de Emprego e Rendimentos (PME/IBGE) e estimar quais seriam os valores mensais deste rendimento medido pela PNAD. Chega-se, então, ao valor médio anual do rendimento dos serviços domésticos. ${ }^{16}$

(15) Supõe-se aqui que não importa a faixa etária, todos são capazes de realizar eficientemente os serviços domésticos que se atribuem.

(16) Esta é a metodologia utilizada pelas Contas Nacionais do Brasil, conforme foi esclarecido pela economista Heloísa Valverde Filgueiras, do Departamento de Contas Nacionais do IBGE. Lembra-se aqui que, enquanto a PNAD refere-se ao país como um todo, a Pesquisa Mensal de Emprego (PME) tem como âmbito apenas as regiões metropolitanas do país. 


\section{A conta dos afazeres domésticos: 2001-2005}

Para fazer a contabilidade dos afazeres domésticos, este estudo utilizou três métodos: pelo primeiro, considerou-se o rendimento médio do trabalho doméstico registrado na PNAD no mês de setembro como sendo o rendimento médio do ano; o segundo método usou as variações mensais do salário mínimo ao longo do ano para fazer variar o valor registrado pela PNAD em setembro; pelo terceiro método usou-se a metodologia das contas nacionais brasileiras, fazendo com que o salário de setembro registrado pela PNAD variasse mensalmente segundo a variação mensal do rendimento do trabalho doméstico registrado pela PME. Em razão da falta de informações da PME para todos os anos deixa-se de apresentar alguns resultados do método 3, salientando-se, contudo, conforme pode ser observado, que os resultados para os anos de 2002 e 2003, para os quais as informações estavam disponíveis, se assemelham aos do método 1. As informações usadas estão discriminadas em Anexo Estatístico que pode ser solicitado pelos leitores aos autores e referem-se ao período 2001-2005. Nesse anexo encontram-se os valores a preços correntes do PIB, o salário mínimo mensal e os cálculos do valor dos afazeres domésticos, bem como o tempo gasto pela população, segundo o sexo, para sua realização.

Como pode ser observado na Tabela 1, a seguir, a participação dos afazeres domésticos no PIB de cada ano é bastante semelhante e sua média é de $11,2 \%$ calculando-se com os valores de setembro, ou de 11,6\% quando calculado pela variação anual da PME para os dois anos com informação. Como a série antiga da PME não estava disponível e como a série nova inicia-se em março de 2002, utilizou-se alternativamente a variação do salário mínimo para considerar as variações mensais da remuneração média do ano de 2001. Comparando-se esse resultado com as outras metodologias, a participação dos afazeres domésticos é em média de $10 \%$. Portanto, os resultados são bastante próximos entre os três métodos utilizados. Como o resultado obtido a partir dos valores da PNAD de setembro não difere substancialmente da metodologia adotada pelas contas nacionais nos anos em que há resultados para ambas, e como só se pode ter resultados para os cinco anos com os valores de setembro da PNAD, os resultados relatados a seguir se referem ao método que considera como média anual o valor de setembro da PNAD. 
Tabela 1

PIB e renda anual com afazeres domésticos - Brasil

\begin{tabular}{|c|c|c|c|c|c|c|c|c|c|c|}
\hline \multirow{2}{*}{$\begin{array}{l}\text { Anos } \\
\text { Métodos }\end{array}$} & \multicolumn{2}{|c|}{2001} & \multicolumn{2}{|c|}{2002} & \multicolumn{2}{|c|}{2003} & \multicolumn{2}{|c|}{2004} & \multicolumn{2}{|c|}{2005} \\
\hline & $\begin{array}{l}\text { Renda } \\
\text { Anual }\end{array}$ & $\begin{array}{c}\% \\
\text { Sobre } \\
\text { PIB }\end{array}$ & $\begin{array}{l}\text { Renda } \\
\text { Anual }\end{array}$ & $\begin{array}{c}\% \\
\text { Sobre } \\
\text { PIB }\end{array}$ & $\begin{array}{l}\text { Renda } \\
\text { Anual }\end{array}$ & $\begin{array}{c}\% \\
\text { Sobre } \\
\text { PIB }\end{array}$ & $\begin{array}{l}\text { Renda } \\
\text { Anual }\end{array}$ & $\begin{array}{c}\% \\
\text { Sobre } \\
\text { PIB }\end{array}$ & $\begin{array}{l}\text { Renda } \\
\text { Anual }\end{array}$ & $\begin{array}{c}\% \\
\text { Sobre } \\
\text { PIB }\end{array}$ \\
\hline Método 1 & 148.653 & 11,4 & 170.238 & 11,5 & 200.283 & 11,8 & 204.791 & 10,5 & 235.350 & 11,0 \\
\hline Método 2 & 131.692 & 10,1 & 153.215 & 10,4 & 177.174 & 10,4 & 184.191 & 9,5 & 207.591 & 9,7 \\
\hline Método 3 & -- & --- & 167.710 & 11,3 & 199.812 & 11,8 & -- & --- & -- & --- \\
\hline PIB & 1.302 .136 & --- & 1.477 .822 & --- & 1.699 .948 & --- & 1.941 .498 & --- & 2.147 .944 & --- \\
\hline
\end{tabular}

Notas: 1) Método 1: Renda semanal com afazeres domésticos da PNAD multiplicada por 52 semanas.

2) Método 2: Renda semanal com afazeres domésticos da PNAD em salários mínimos do mês de setembro, multiplicada pelo total de salários mínimos do ano respectivo.

3) Método 3: Renda semanal com afazeres domésticos calculada com base na variação do rendimento médio mensal das pessoas ocupadas em serviços domésticos remunerados segundo a PME/IBGE.

Fonte: Dados do IBGE: PNAD (2001-2005) e Novas Contas Nacionais (2007). Elaboração dos autores. 
Em termos de valor, caso se resolvesse mensurar os afazeres domésticos no PIB brasileiro, significaria acrescentar ao PIB do ano de $2001 \mathrm{R} \$ 148,7$ bilhões; no ano de 2002 R \$ 170,2 bilhões; em 2003 R \$ 200,3 bilhões; em 2004 $\mathrm{R} \$ 204,8$ bilhões e em 2005, R \$ 235,4 bilhões. Caso esse percentual se mantivesse constante em 2006, tal como ocorreu nos cinco anos anteriores, se acresceriam ao PIB brasileiro R $\$ 260,2$ bilhões e o PIB de 2006 seria de $\mathrm{R} \$ 2.583$ bilhões e não de $\mathrm{R} \$ 2.322,8$ bilhões, como o IBGE anunciou.

Tendo em vista o número de horas ocupadas pelas mulheres em afazeres domésticos, que em média é o dobro das ocupadas pelos homens, e o número de mulheres nessa função, que é em média 2,2 vezes o número de homens, o valor gerado pelos afazeres domésticos por parte das mulheres é, em média, de $82 \%$ e os $18 \%$ restantes o valor criado pelos homens. Esses $82 \%$ de afazeres domésticos realizados pelas mulheres no ano de 2006 teriam representado $\mathrm{R} \$ 213$ bilhões.

Finalmente, é importante chamar a atenção para o fato de que o percentual do PIB gerado pelos afazeres domésticos é próximo ao PIB do Estado do Rio de Janeiro, que vem a ser segundo estado com o maior PIB do país.

\section{Conclusão}

Este artigo procurou medir aquilo que grande parte das pessoas busca ignorar: o valor que os afazeres domésticos têm para nossa vida e nosso bem-estar. E, na teoria econômica, essa discriminação é proposital: os serviços gerados na execução dos afazeres domésticos não são contados no PIB dos países; vale dizer, não são valorados, e por isso, consequentemente não reconhecidos socialmente. Provavelmente, isso se origina na histórica discriminação da mulher nas sociedades, a quem foram os afazeres domésticos delegados. Ignorá-los, por sua vez, reforça o conceito da invisibilidade do trabalho feminino.

Utilizando-se dos procedimentos usuais de estimativas de bens ou serviços não mensurados por estatísticas econômicas, estatísticas demográficas e sociais originárias da Pesquisa Nacional por Amostra de Domicílios (PNAD) do Instituto Brasileiro de Geografia e Estatística (IBGE) e os procedimentos técnicos similares aos usados para a contabilização do Produto Interno Bruto (PIB), conclui-se que essas atividades valem cerca de $11,2 \%$ do PIB brasileiro e que corresponderam no ano de 2006 a R\$260,2 bilhões. Ou seja, o PIB nacional aumentaria nesse valor caso a sociedade contabilizasse essas tarefas ligadas à reprodução da vida. Além do mais, $82 \%$ desse trabalho ou, pelo ângulo monetário, daquele valor, cerca de $\mathrm{R} \$ 213$ bilhões foram gerados pelas mulheres.

É preciso esclarecer que chegou-se a esse montante por que a economia brasileira paga baixíssimos salários, e o serviço doméstico remunerado é uma das atividades econômicas de piores salários na economia, o que vai refletir-se nessa 
Hildete Pereira de Melo / Claudio Monteiro Considera / Alberto Di Sabbato

medição (Melo et al., 2002). Seguramente essa participação será diferente nos países europeus e nos EUA, locais onde as disparidades salariais não são tão gritantes. As remunerações são maiores, mas em compensação o número de horas e pessoas dedicadas a afazeres domésticos é bem menor. Lá os casais dispõem de diversos bens e serviços auxiliares que substituem os afazeres domésticos e, por serem mercantis, já estão medidos no PIB.

\section{Referências bibliográficas}

AGUIAR, Neuma. Gênero e ciências humanas - desafio às ciências desde a perspectiva das mulheres. Rio de Janeiro: Editora Rosa dos Tempos/Record, 1997.

Múltiplas temporalidades de referência: trabalho doméstico e trabalho remunerado em uma plantação canavieira. Revista Gênero, Núcleo Transdisciplinar de Estudos de Gênero (NUTEG) da Universidade Federal Fluminense, v. 1, n. 2, 1. semestre 2001.

BEAUVOIR, Simone de. O segundo sexo. 2. ed. Rio de Janeiro: Editora Nova Fronteira, 1980. 2 v. Primeira edição francesa de 1949 de Editions Gallimard, 1949.

BECKER, Gary. The economic approach to human behaviour. Chicago: University of Chicago Press, 1976.

Family economics and the macro behaviour. American Economic Review, v. 78, n. 1, p.1-13, 1986.

A treatise on the family. Harvard University Press, 1991.

BENNETTI, C.; CARTELIER, J. Marchands, salariat et capitalistes. Paris: Maspero, 1981.

BLAY, Eva. Trabalho domesticado: a mulher na indústria paulista. São Paulo: Ática, 1978.

BOSERUP, E. Women's role in economic development. New York: Saint Martin's Press, 1970.

CARTELIER, L. State and wage labor. Capital and Class, New York, v. 18, 1980.

DEDECCA, Claudio Salvadori. Tempo, trabalho e gênero. In: COSTA, Ana A.; OLIVEIRA, Eleonora M. de; LIMA, Maria Ednalva B. de; SOARES, Vera; (Org.). Reconfiguração das relações de gênero no trabalho. São Paulo: CUT, 2004.

DE VROEY, M. La théorie de la valeur de Marx: une reinterpretation. Cahier d'Economie Politique, Paris, v. 9, 1984.

FRIEDAN, Betty. The second stage. New York: Summer Book, 1982.

HARDING, Sandra. The science question in feminism. Ithaca: Cornell University Press, 1986.

IBGE - Instituto Brasileiro de Geografia e Estatística. Sistemas de Contas Nacionais Brasil, 2007; PNAD, 2001-2005; PME, 2002 e 2003.

KALECKI, M. Essays on developing economics. Sussex: Harvester Press, 1979. 
KELLER, Evelyn Fox. Reflections on gender and science. New Haven: Yale University Press, 1985.

LOPES, F. R.; SERRANO, F. L. P. Marx e a mercadoria força de trabalho. In: ENCONTRO NACIONAL DE ECONOMIA, 16, 1986. Brasília: Anpec. / Texto para Discussão, IEI/UFRJ, n. 120, 1987.

MACHADO, J.; SERRANO, F. L. P. Uma nota sobre a crise da teoria econômica. Literatura Econômica, Rio de Janeiro, Inpes/Ipea, ago. 1986.

MARX, K. O capital. São Paulo: Abril Cultural, 1983. (Os Economistas).

; ENGELS, F. A ideologia alemã. México: Editorial Grijalbo, 1977.

MEILlASSOUX, Claude. Femmes, greniers et capitaux. Paris: Maspéro, 1979.

MELO, Hildete Pereira de; PENA, Maria Valéria. A condição feminina e a teoria econômica. Literatura Econômica, Rio de Janeiro, Inpes/Ipea, fev. 1985.

; SERRANO, Franklin. A mulher como objeto da teoria econômica. In: AGUIAR, Neuma. Gênero e ciências humanas - desafio às ciências desde a perspectiva das mulheres. Rio de Janeiro: Editora Rosa dos Tempos/Record, 1997.

; SABBATO, A.; SOUZA, C. F.; ROCHA, F.; FERRAZ, G., HORTA, M. H.; DWECK, R. H.; WADDINGTON, S. Os serviços no Brasil. Brasília, DF: Ministério da Indústria, do Comércio e do Turismo; Ipea, Anpec, 1998.

; PESSANHA, M. C.; PARREIRAS, L. E. Da cozinha para o mercado: a evolução dos rendimentos dos trabalhadores domésticos nos anos 90. In: GALEAZZI, Irene M. S. Mulher e trabalho. Porto Alegre: FEE, FGTAS/SINE, DIEESE, SEADE/SP, FAT, 2002.

MICHEL, Andrée. Les femmes dans la societé marchande. Paris: Presses Universitaires de France, 1978.

MILL, John Stuart. A sujeição das mulheres. In: MILL, J. Stuart; MILL, Harriet Taylor. Ensaios sobre a igualdade sexual. Ed. e introduzido por Alice Rossi. Trad. por Leila de Souza Mendes Pereira. The University of Chicago Press. Literatura Econômica, Rio de Janeiro, Ipea/Inpes, v. 7, n. 1, fev. 1985.

NELSON, Julie. Gender, metaphor and the definition of economics. Economics and Philosophy, Cambridge University Press, v. 8, p. 103-125, 1992.

NICHOLSON, Linda. Feminismo e Marx: integrando o parentesco com o econômico. In: BENHABIB, S.; CORNEL, D. (Ed.). Feminismo como crítica da modernidade. Rio de Janeiro: Editora Rosa dos Tempos, 1987.

OAKLEY, Ann. Woman's work, the housewife, past and present. New York: Vintage Books, 1974.

SAFFIOTI, Heleieth, I. B. A mulher na sociedade de classe: mito e realidade. Petrópolis: Editora Vozes, 1976.

SARTI, Cynthia. A sedução da igualdade: trabalho, gênero e classe. In: SCHPUN, Mônica Raisa. Gênero sem fronteiras: oito olhares sobre mulheres e relações de gênero. Florianópolis: Editora de Mulheres, 1997. 
Hildete Pereira de Melo / Claudio Monteiro Considera / Alberto Di Sabbato

SAYERS, Janet. Feminismo e ciência. In: ROSE, Steven; APPIGNANESI, Lisa (Org.). Para uma nova ciência. Lisboa: Gradiva, 1989.

SCAVONE, Lucila (Org.). Tecnologias reprodutivas: gênero e ciência. São Paulo: Ed. Unesp, 1996.

SCOTT, Joan Wallach. Gender and the politics of history. New York: Columbia University Press, 1994.

TAHAHITE, Fatiha-Hakili. Pour une problematique du procès de travail domestique em le sexe du travail. Grenoble: Presses Universitaires de Grenoble, 1984.

UN. System of national accounts. 1993. cap. IV: A conta de produção. 